\title{
Changes in cause-specific mortality trends across occupations in working-age Japanese women from 1980 to 2015: a cross-sectional analysis
}

Bibha Dhungel ${ }^{1,2+}$, Kuniyasu Takagi $^{3+}$, Shijan Acharya ${ }^{4}$, Koji Wada $^{3^{*}}$ and Stuart Gilmour ${ }^{1}$

\begin{abstract}
Background: Reducing health inequalities is an important public health challenge. Many studies have examined the widening health gap by occupational class among men, but few among women. We therefore estimated variation in absolute and relative mortality by occupational category across four leading causes of mortality-cancer, ischaemic heart disease, cerebrovascular disease, and suicide - to explore how occupational class is associated with health among working women aged 25-64 in Japan.
\end{abstract}

Methods: We conducted a repeated cross-sectional study using Poisson regression analysis on each five-yearly mortality data from 1980 to 2015, obtained from the National Vital Statistics and the Japanese Population Census.

Results: There was a decreasing trend in mortality from all cancers, ischaemic heart disease, cerebrovascular disease, and suicide among women in all occupational groups from 1980 to 2015. Agriculture workers had higher risk of mortality than professional workers for all four causes of death. The absolute difference in mortality rates for all cancers and cerebrovascular disease was higher in 2000-2015 than 1980-1995. The mortality trend among clerks and sales workers decreased after 2000, except for suicide.

Conclusions: Mortality rates from all four causes are higher among agriculture workers compared to professional workers, and attention is needed to reduce this mortality gap. Continuous monitoring of ongoing mortality trends is essential to ensure better health and wellbeing in Japan.

Keywords: Mortality, Japan, Inequality, Occupation, Working age, Women, Cancer, Cerebrovascular disease, Ischaemic heart disease, Suicide

\section{Background}

Reducing health inequalities is a critical task in public health and imposes an enormous challenge. Addressing the social predictors of health is crucial. The Marmot

\footnotetext{
*Correspondence: kwada@iuhw.ac.jp

${ }^{\dagger}$ Bibha Dhungel and Kuniyasu Takagi have contributed equally to this work.

${ }^{3}$ Graduate School of Medicine, International University of Health and Welfare, Akasaka, Tokyo, Japan

Full list of author information is available at the end of the article
}

Review, among many other previous studies, showed increasing inequalities between occupational classes [1]. Socio-economic factors such as occupation are known to affect health outcomes in life [2-4]. Recent findings also suggest that economic crises have been associated with a widening health gap by occupational class among women [5-7]. Relative measures are widely used to measure reduction in mortality. A reduction in both absolute and relative risk is important [8], but a decline in absolute mortality is essential to eliminate excess mortality [9]. 
However, few studies have examined how occupational class is associated with health among women in Japan [10] and how mortality inequality differs by the leading causes of death.

Japan had a considerable improvement in population health after the mid-1990s and currently has one of the best population health systems in the world [11]. However, there has been an increase in premature all-cause adult mortality, resulting in the increase in relative health inequality across occupations [12, 13]. Previous studies suggest that the inverse association between socioeconomic status and mortality was lost after the financial crises in the late 1990s when there was a very large increase in mortality among professional/management workers[7]. However, these studies focused mainly on working-aged men. In 2015, Japanese women constituted $43 \%$ of the total labour force and their unemployment rate was $3.1 \%$ [14]. The number of women in the workforce is increasing and women aged 20-64 years currently constitute about $70 \%$ of female workers. However, around $44 \%$ of the employed Japanese women are engaged in part-time or temporary work compared to only $11 \%$ of employed men [14]. We therefore believe that mortality inequalities among Japanese women may be different from those among Japanese men or women in other parts of the world. In this study, we estimated the variation in absolute and relative mortality across various occupational categories and diseases and explored the inequalities in cause-specific mortality between occupational categories.

\section{Methods}

We conducted a repeated cross-sectional study on each five-yearly mortality data, from 1980 to 2015 . We obtained the mortality data from the National Vital Statistics [15] along with occupation-specific population data from the Japanese Population Census [16] conducted in the same year. The databases were merged using populations by occupation and age group from the census with deaths data by occupation and age group from the vital statistics data. We obtained permission from the Ministry of Health, Labour and Welfare of Japan for secondary use of the data. Information on occupation for the deceased was acquired from the death certificate, which contains the deceased person's occupation before death, as given by a family member. Occupations were categorised following the Japan Standard Occupational Classification [17], as professionals (professional and technical workers), clerks, sales workers, service workers, agricultural workers (agricultural, forestry, fishery workers), manufacturing workers, managers (managers and official), transport workers and security workers. The proportion of female workers in the managers, transport, and security categories was very low, so we combined them and analysed them as 'Other'.

The quality of data from the Japanese Vital Registration system is high with less than $10 \%$ of ill-defined codes on the registrations [18]. We excluded $1.3 \%$ of the ill-defined codes in the current dataset from the analysis. The causes of death were classified using the International Classification of Disease ninth revision for the years 1980, 1985 and 1990 and tenth revision for the years 1995, 2000, 2010 and 2015. We analysed the four leading causes of death--cancer, ischaemic heart disease, cerebrovascular disease, and suicide-among 25 to 64-year-old Japanese women [19].

\section{Analysis}

We analysed data from female workers aged 25-64 years. We excluded workers aged $<25$ years because this includes students, and those aged $>64$ years because this is the age of retirement in Japan. Following standard practice for comparing rates across years, we standardised the data using the 1985 standard population of Japan in 5-year age intervals. We computed age-standardised rates for each five years from 1980 to 2015 across occupations to analyse the patterns in trends of cause-specific mortality rates.

We used a Poisson regression analysis to measure the relative mortality inequality across occupations separately by cause of death. The estimated mortality rate ratios were adjusted for time (year), age category, occupation, and a step variable. The step variable was used to indicate whether the death occurred on or before 1995, or on 2000 or after reflecting the potential change of the economic crisis in the mid-1990s across occupational categories. The first year in the data series was set as 0 , while following years as 5,10 up to 35 corresponding to the year 2015. An interaction between mortality and the step variable was also included in the model. A linear combination of the interaction variable and trend was used to compare the occupation-specific mortality rate on or before 1995, and 2000 or after. We used Stata IC version 15.1 for the analysis.

\section{Analysis of mortality rates}

Poisson regression model was used with population by occupation as an offset. We expressed the fundamental distribution of data as

$$
y_{i} \sim \operatorname{Poisson}\left(\mu_{i}\right)
$$

where $y_{i}$ is the number of deaths from specific cause occurring at rate $\mu_{i}$ in population $n_{i}$.

$\mu_{i}$ is related to the covariates through a two-way interaction Poisson regression model as follows 


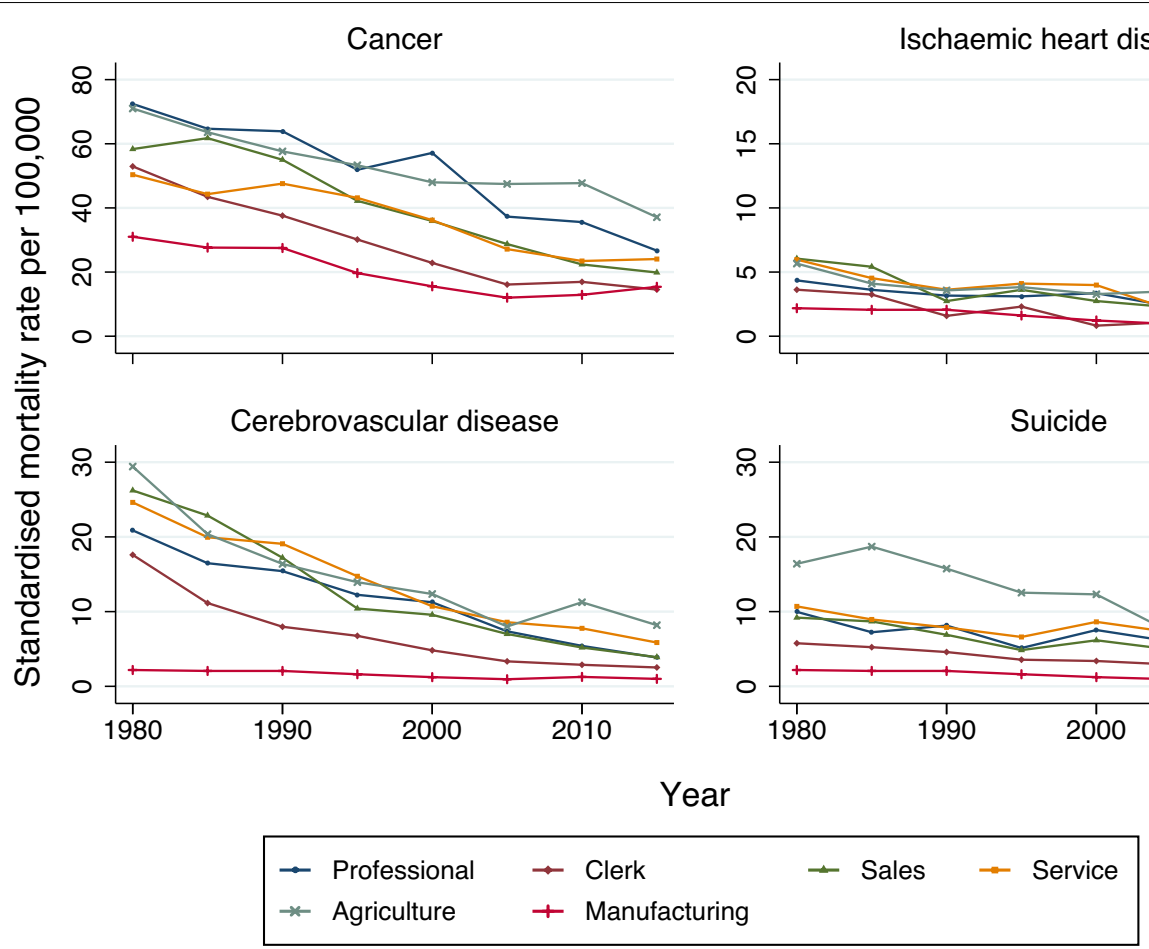

Fig. 1 Trends in age-standardised mortality rates per 100,000 by occupation separately by cause of death

Table 1 Number and proportion of female workers aged 25-64 by occupation from 1980 to 2015

\begin{tabular}{|c|c|c|c|c|c|c|c|c|}
\hline $\begin{array}{l}\text { Occupational } \\
\text { category/Year }\end{array}$ & $\begin{array}{l}1980 \\
\text { n (\%) }\end{array}$ & $\begin{array}{l}1985 \\
\text { n (\%) }\end{array}$ & $\begin{array}{l}1990 \\
\text { n (\%) }\end{array}$ & $\begin{array}{l}1995 \\
\text { n (\%) }\end{array}$ & $\begin{array}{l}2000 \\
\text { n (\%) }\end{array}$ & $\begin{array}{l}2005 \\
\text { n (\%) }\end{array}$ & $\begin{array}{l}2010 \\
\text { n (\%) }\end{array}$ & $\begin{array}{l}2015 \\
\text { n (\%) }\end{array}$ \\
\hline Professional & $1,507,610(9.0)$ & $1,891,400(10.5)$ & $2,250,231(11.8)$ & $2,684,971(13.5)$ & $3,094,599(15.1)$ & $3,459,894(16.7)$ & $3,580,129(18.0)$ & $3,953,581(19.9)$ \\
\hline Clerk & $3,369,822(20.1)$ & $4,248,922(23.6)$ & $5,155,485(27.0)$ & $5,748,954(28.9)$ & $6,289,031(30.7)$ & $6,422,961(31.0)$ & $5,849,554(29.4)$ & $5,931,116(29.9)$ \\
\hline Sales & $2,586,857(15.4)$ & $2,447,212(13.6)$ & $2,534,197(13.3)$ & $2,702,863(13.6)$ & $2,618,387(12.8)$ & $2,561,132(12.4)$ & $2,600,469(13.1)$ & $2,482,037(12.5)$ \\
\hline Service & $2,106,305$ (12.6) & $2,173,931(12.1)$ & 2,263,285 (11.8) & $2,516,848(12.7)$ & $2,825,178(13.8)$ & $3,207,147(15.5)$ & $3,610,654(18.2)$ & $3,512,739(17.7)$ \\
\hline Agriculture & $2,471,427(14.7)$ & $2,029,368(11.3)$ & $1,478,304(7.7)$ & $1,055,672(5.3)$ & $755,524(3.7)$ & $600,419(2.9)$ & $442,060(2.2)$ & $367,011(1.9)$ \\
\hline Manufacturing & $4,456,927(26.6)$ & $4,911,261(27.3)$ & $5,158,278(27.0)$ & $4,862,147(24.5)$ & $4,664,292(22.7)$ & $4,228,532(20.4)$ & $3,563,491(17.9)$ & $3,346,382(16.9)$ \\
\hline Others & $273,332(1.16)$ & $280,377(1.6)$ & $285,498(1.4)$ & $318,119(1.5)$ & $272,623(1.2)$ & $251,835(1.1)$ & $229,540(1.2)$ & $253,059(1.2)$ \\
\hline
\end{tabular}

$$
\begin{aligned}
\ln \left(\mu_{i}\right)= & \alpha+\ln \left(n_{i}\right)+\beta_{1} x_{i 1}+\beta_{2} x_{i 2} \\
& +\beta_{3} x_{i 3}+\beta_{4} x_{i 4}+\beta_{5} x_{i 1} x_{i 3}
\end{aligned}
$$

where $\alpha$ is the intercept term; $x_{i 1}$ is the year $(0=1980$, $5=1985, \quad 10=1990,15=1995,20=2000,25=2005$, $30=2010,35=2015) ; x_{i 2}$ is the age category $(1=25-34$, $2=35-44,3=45-54,4=55-64) ; x_{i 3}$ is the occupational category $(1=$ professional, $2=$ clerk, $3=$ sales, $4=$ service, $5=$ agriculture, $6=$ manufacturing, $7=$ others); and $x_{i 4}$ is the step variable (0 for years 1980, 1985, 1990 and 1995, 1 for years 2000, 2005, 2010, 2015).

\section{Results}

Table 1 shows the proportion of female workers in each occupation from 1980 to 2015 . The proportion of women in professional, clerical and service categories increased over time, and those in sales, agriculture, and manufacturing decreased. The smallest groups of women workers were managers, and transport and security workers.

Figure 1 shows the cause-specific trends in mortality rates per 100,000 among female workers. Cancer and cerebrovascular mortality rates decreased steadily across all occupational categories until mid 2000s. However, mortality rates from ischaemic heart disease and suicide 
have increased in some occupational categories in recent years.

Table 2 shows the absolute and relative difference in age-standardised cause-specific mortality rates across occupations for 1980-1995 and 2000-2015. In 2015, the highest rates in mortality for all four causes of death was among agricultural workers, while clerical workers had the lowest rate in mortality. We found decreasing mortality rates by cause among women in all occupational categories from 1980 and 2015. The absolute difference in mortality from all four causes of death was larger during 1980-1995 than 2000-2015 in nearly all occupational categories. However, the relative change in mortality for all cancer, ischaemic heart disease and cerebrovascular disease was larger during 2000-2015 than 1980-1995 among professional, sales and service workers. Mortality rates from all four causes of death were highest among agricultural workers in 2015. Professional workers had the largest absolute and relative difference in mortality between 2000 and 2015 for all cancer, ischaemic heart disease and cerebrovascular disease. Between 1985 and 2015 , clerks had the highest relative decrease in mortality rates from all cancers, ischaemic heart disease, and cerebrovascular disease. However, reduction in absolute mortality was much less among clerks and manufacturing workers from 1980 to 2015 for all causes of mortality.

Table 3 shows the risk of mortality across occupational categories obtained from Poisson regression analysis. Rate ratio for mortality among agriculture workers for all four causes of death is higher than among professionals. Risk of mortality for service workers is higher than professionals for ischaemic heart disease, cerebrovascular disease, and suicide, while for cancer, the risk ratio is 0.78 (95\% Confidence Interval, 0.75-0.81). For clerical

Table 2 Absolute and relative difference in mortality rates for 1980-1995, and 2000-2015 across occupations

\begin{tabular}{|c|c|c|c|c|c|c|c|c|c|c|}
\hline \multirow{2}{*}{$\begin{array}{l}\text { Cause of death } \\
\text { and occupational } \\
\text { category }\end{array}$} & \multicolumn{4}{|c|}{$\begin{array}{l}\text { Age-standardised mortality } \\
\text { rates per } 100,000\end{array}$} & \multicolumn{3}{|c|}{ Absolute Difference $^{a}$} & \multicolumn{3}{|c|}{ Percentage change $(\%)^{b}$} \\
\hline & 1980 & 1995 & 2000 & 2015 & 1980-1995 & 2000-2015 & 1980-2015 & 1980-1995 & $2000-2015$ & 1980-2015 \\
\hline \multicolumn{11}{|l|}{ All cancers } \\
\hline Professional & 72.4 & 51.9 & 57.1 & 26.7 & -20 & -30 & -46 & -28 & -53 & -63 \\
\hline Clerk & 52.9 & 30.2 & 22.8 & 14.5 & -23 & -8 & -38 & -43 & -35 & -73 \\
\hline Sales & 58.4 & 42.2 & 35.9 & 19.9 & -16 & -16 & -39 & -27 & -45 & -66 \\
\hline Service & 50.4 & 43.1 & 36.2 & 24.1 & -7 & -12 & -26 & -14 & -33 & -52 \\
\hline Agriculture & 71.0 & 53.3 & 48.0 & 37.1 & -18 & -11 & -34 & -25 & -23 & -48 \\
\hline Manufacturing & 31.0 & 19.7 & 15.6 & 15.4 & -11 & 0 & -16 & -35 & 0 & -50 \\
\hline \multicolumn{11}{|c|}{ Ischaemic heart disease } \\
\hline Professional & 4.4 & 3.1 & 3.4 & 1.1 & -1 & -2 & -3 & -23 & -59 & -75 \\
\hline Clerk & 3.6 & 2.3 & 0.8 & 0.7 & -1 & 0 & -3 & -28 & 0 & -81 \\
\hline Sales & 6.0 & 3.6 & 2.7 & 1.2 & -2 & -1 & -5 & -33 & -37 & -80 \\
\hline Service & 6.0 & 4.1 & 4.0 & 1.7 & -2 & -2 & -4 & -33 & -50 & -72 \\
\hline Agriculture & 5.7 & 3.8 & 3.3 & 2.4 & -2 & -1 & -3 & -35 & -30 & -58 \\
\hline Manufacturing & 2.2 & 1.6 & 1.2 & 1.0 & -1 & 0 & -1 & -45 & 0 & -55 \\
\hline \multicolumn{11}{|c|}{ Cerebrovascular disease } \\
\hline Professional & 20.9 & 12.2 & 11.3 & 3.9 & -9 & -7 & -17 & -43 & -62 & -81 \\
\hline Clerk & 17.6 & 6.8 & 4.8 & 2.5 & -11 & -2 & -15 & -62 & -42 & -86 \\
\hline Sales & 26.2 & 10.4 & 9.6 & 3.9 & -16 & -6 & -22 & -61 & -62 & -85 \\
\hline Service & 24.6 & 14.7 & 10.7 & 5.9 & -10 & -5 & -19 & -41 & -47 & -76 \\
\hline Agriculture & 29.4 & 13.9 & 12.4 & 8.2 & -15 & -4 & -21 & -51 & -32 & -72 \\
\hline Manufacturing & 11.8 & 6.6 & 4.4 & 3.4 & -5 & -1 & -8 & -42 & -23 & -71 \\
\hline \multicolumn{11}{|l|}{ Suicide } \\
\hline Professional & 10.0 & 5.1 & 7.5 & 4.8 & -5 & -3 & -5 & -50 & -40 & -52 \\
\hline Clerk & 5.8 & 3.6 & 3.4 & 2.6 & -2 & -1 & -3 & -34 & -29 & -55 \\
\hline Sales & 9.2 & 4.8 & 6.2 & 3.8 & -4 & -2 & -5 & -43 & -32 & -59 \\
\hline Service & 10.7 & 6.6 & 8.6 & 6.2 & -4 & -2 & -5 & -37 & -23 & -42 \\
\hline Agriculture & 16.4 & 12.5 & 12.3 & 8.7 & -4 & -4 & -8 & -24 & -33 & -47 \\
\hline Manufacturing & 5.1 & 2.9 & 3.0 & 3.3 & -2 & 0 & -2 & -39 & 0 & -35 \\
\hline
\end{tabular}

${ }^{a}$ Absolute difference in age-standardised mortality rates per 100,000 between 1980 and $2015 ;{ }^{b}$ Difference expressed as a percentage of rates in 1980 or 2000 
Table 3 Mortality inequalities across occupation among female workers aged 25-64 in Japan

\begin{tabular}{|c|c|c|c|}
\hline $\begin{array}{l}\text { Cause of death and } \\
\text { occupational category }\end{array}$ & Rate ratio $^{a}$ & $\begin{array}{l}95 \% \text { confidence } \\
\text { interval }\end{array}$ & $p$ value \\
\hline \multicolumn{4}{|l|}{ All cancers } \\
\hline Professional & Reference & & \\
\hline Clerk & 0.50 & $(0.48-0.52)$ & $<0.01$ \\
\hline Sales & 0.76 & $(0.73-0.80)$ & $<0.01$ \\
\hline Service & 0.78 & $(0.75-0.81)$ & $<0.01$ \\
\hline Agriculture & 1.26 & $(1.19-1.34)$ & $<0.01$ \\
\hline Manufacturing & 0.38 & $(0.36-0.40)$ & $<0.01$ \\
\hline Other & 4.86 & $(4.61-5.11)$ & $<0.01$ \\
\hline \multicolumn{4}{|l|}{ Ischaemic heart disease } \\
\hline Professional & Reference & & \\
\hline Clerk & 0.46 & $(0.37-0.55)$ & $<0.01$ \\
\hline Sales & 1.01 & $(0.81-1.20)$ & 0.947 \\
\hline Service & 1.20 & $(0.99-1.40)$ & 0.037 \\
\hline Agriculture & 1.70 & $(1.33-2.07)$ & $<0.01$ \\
\hline Manufacturing & 0.54 & $(0.43-0.64)$ & $<0.01$ \\
\hline Other & 5.79 & $(4.51-7.07)$ & $<0.01$ \\
\hline \multicolumn{4}{|l|}{ Cerebrovascular disease } \\
\hline Professional & Reference & & \\
\hline Clerk & 0.56 & $(0.50-0.61)$ & $<0.01$ \\
\hline Sales & 1.02 & $(0.92-1.13)$ & 0.671 \\
\hline Service & 1.31 & $(1.19-1.43)$ & $<0.01$ \\
\hline Agriculture & 1.52 & $(1.33-1.71)$ & $<0.01$ \\
\hline Manufacturing & 0.54 & $(0.49-0.60)$ & $<0.01$ \\
\hline Other & 4.41 & (3.85-4.98) & $<0.01$ \\
\hline \multicolumn{4}{|l|}{ Suicide } \\
\hline Professional & Reference & & \\
\hline Clerk & 0.50 & $(0.45-0.55)$ & $<0.01$ \\
\hline Sales & 0.77 & $(0.68-0.86)$ & $<0.01$ \\
\hline Service & 1.20 & $(1.09-1.32)$ & $<0.01$ \\
\hline Agriculture & 1.97 & $(1.70-2.25)$ & $<0.01$ \\
\hline Manufacturing & 0.49 & $(0.44-0.55)$ & $<0.01$ \\
\hline Other & 4.83 & $(4.18-5.49)$ & $<0.01$ \\
\hline
\end{tabular}

a Rate ratio obtained from Poisson regression analysis adjusting for year, age category, step variable (mortality before or after 2000), occupation and interaction of step variable and occupation

workers and manufacturing workers, the risk of mortality is lower than among professionals. Full result of the Poisson regression analysis is shown in Table A1 [see Additional file 1].

Table 4 shows the rate ratios and confidence intervals for mortality rates on or after 2000 compared with 1995 and before, using a linear combination of variables from the Poisson regression analysis. Mortality from cancer, ischaemic heart disease, and cerebrovascular disease among clerical and sales workers decreased significantly by over $20 \%$ on or after 2000 compared with 1995 or before. However, mortality from cancer and ischaemic heart disease among
Table 4 Relative change in occupation-specific mortality on or after 2000 compared with 1995 or before among female workers

\begin{tabular}{|c|c|c|c|}
\hline $\begin{array}{l}\text { Cause of death and } \\
\text { occupational category }\end{array}$ & Rate ratio ${ }^{a}$ & $\begin{array}{l}95 \% \text { confidence } \\
\text { interval }\end{array}$ & $p$ value \\
\hline \multicolumn{4}{|l|}{ All cancers } \\
\hline Professional & 0.97 & $(0.92-1.03)$ & 0.323 \\
\hline Clerk & 0.70 & $(0.67-0.74)$ & $<0.001$ \\
\hline Sales & 0.80 & $(0.76-0.84)$ & $<0.001$ \\
\hline Service & 0.94 & $(0.90-0.99)$ & 0.024 \\
\hline Agriculture & 1.17 & $(1.10-1.25)$ & $<0.001$ \\
\hline Manufacturing & 0.81 & $(0.77-0.86)$ & $<0.001$ \\
\hline Other & 1.59 & $(1.49-1.70)$ & $<0.001$ \\
\hline \multicolumn{4}{|l|}{ Ischaemic heart disease } \\
\hline Professional & 1.16 & $(0.91-1.48)$ & 0.235 \\
\hline Clerk & 0.75 & $(0.60-0.93)$ & 0.009 \\
\hline Sales & 0.82 & $(0.67-1.01)$ & 0.057 \\
\hline Service & 0.91 & $(0.76-1.09)$ & 0.308 \\
\hline Agriculture & 1.33 & $(1.06-1.66)$ & 0.013 \\
\hline Manufacturing & 0.93 & $(0.76-1.13)$ & 0.441 \\
\hline Other & 1.66 & $(1.27-2.16)$ & $<0.001$ \\
\hline \multicolumn{4}{|l|}{ Cerebrovascular disease } \\
\hline Professional & 1.10 & $(0.98-1.24)$ & 0.107 \\
\hline Clerk & 0.88 & $(0.79-0.97)$ & 0.015 \\
\hline Sales & 0.83 & $(0.75-0.92)$ & $<0.001$ \\
\hline Service & 1.01 & $(0.92-1.10)$ & 0.911 \\
\hline Agriculture & 1.11 & $(0.98-1.25)$ & 0.111 \\
\hline Manufacturing & 0.91 & $(0.82-1.01)$ & 0.068 \\
\hline Other & 1.52 & $(1.31-1.75)$ & $<0.001$ \\
\hline \multicolumn{4}{|l|}{ Suicide } \\
\hline Professional & 1.45 & $(1.28-1.66)$ & $<0.001$ \\
\hline Clerk & 1.03 & $(0.91-1.16)$ & 0.633 \\
\hline Sales & 1.00 & $(0.88-1.15)$ & 0.975 \\
\hline Service & 1.35 & $(1.20-1.53)$ & $<0.001$ \\
\hline Agriculture & 1.16 & $(0.99-1.34)$ & 0.060 \\
\hline Manufacturing & 1.00 & $(0.88-1.14)$ & 0.956 \\
\hline Other & 1.99 & $(1.66-2.38)$ & $<0.001$ \\
\hline
\end{tabular}

${ }^{a}$ Rate ratio on or after 2000 compared to 1995 or before obtained from Poisson regression analysis adjusting for year, age category, step variable (mortality before or after 2000), occupation and interaction of step variable and occupation

agricultural workers, and from suicide among professional and service workers increased significantly after 2000 .

\section{Discussion}

This study found a decreasing trend in mortality from all cancer deaths combined, ischaemic heart disease, cerebrovascular disease, and suicide among women in all occupational groups from 1980 to 2015. Mortality risk among agricultural workers was higher, while among manufacturing and clerical workers were lower than among professionals for all four causes of deaths. 
The absolute decline in mortality rates from all cancers and cerebrovascular disease was higher in 2000-2015 than 1980-1995. After 2000, clerks and sales workers had a decreasing trend in mortality from all causes except suicide. However, the rates of mortality from all four causes among agriculture workers increased slightly after 2000 .

Previous research has identified inequalities in Japanese women's mortality profiles. The risk of stroke is higher, while the risk of ischaemic heart disease is lower among Asians [20]. A study found a higher incidence of stroke among Japanese women with Junior High Schooland College-level education than women with High School-level education, demonstrating a U-shaped association [21]. The risk factors for ischaemic heart disease have changed in women as they have in the population as a whole, and the downward trends in mortality are consistent with these gains [22]. The rate of smoking, which is a major risk factor for cerebral infarction [23], is generally low among Japanese women of all ages [20]. During the 1980s and 1990s, public health endeavours focused on stroke and other cerebrovascular diseases. The prevalence of hypertension decreased with improvements in lifestyle, reduction in salt intake among women and expanding coverage of medications for hypertension from 1980 to 2013 [24, 25]

The cancer mortality rates across all occupational categories of Japanese women, which have been declining since the early 1980s, decreased further after the Cancer Control Act was approved in 2006 [26]. With advances in treatment and improved prognosis for breast cancer, which is the most common cancer in Japanese women, the survival rate has improved [27], leading to a significant reduction in mortality rates. There are socio-economic inequalities in cancer incidence among female workers in Japan [28], but public health efforts have resulted in population-wide changes, leading to a reduction in cancer mortality rates. However, cervical screening rates in Japanese women remain low and vaccination programs against human papillomavirus have stalled [29], so gains in this other common cause of cancer mortality are threatened. Reinstatement of the human papillomavirus vaccination program and enhanced efforts on cervical screening are needed to continue to improve cancer mortality rates in the future.

Japan has one of the highest suicide rates in the world. The rate, however, has been decreasing in recent years with 18.9 per 100,000 population in 2015 [30, 31]. We found stable suicide rates across all occupational categories except professional and service workers. Previous studies reported that nurses, doctors, dentists, pharmacists and police officers are at higher risk of suicide [32, 33]. The impact of socioeconomic factors on suicide in greater in Japan compared to other Organisation for Economic Co-operation and Development countries [34, 35]. Suicide has been identified as a potential contributor to the rise in inequalities in mortality because studies suggest associations between increasing suicide rates and the global financial crisis [7]. Recent work on excess suicide mortality among Japanese women during the coronavirus pandemic suggests that Japanese women are more vulnerable to socio-economic disruption than men, and extra prevention activities may be required in times of economic or social disturbance [36]. This highlights the importance of suicide prevention to reduce inequalities in mortality, especially during turbulent economic conditions.

We found a decrease in both absolute and relative mortality across all occupations for 1980-1995 and 2000-2015. Similarly, mortality from all cancers, ischaemic heart disease and cerebrovascular disease decreased significantly after 2000 among clerical and sales workers compared with before 1995. Studies suggest that women in lower socio-economic classes in Japan are more likely to take risky jobs, resulting in higher mortality rates [37]. This potentially explains the higher rates of mortality among agricultural workers from all four causes. However, these higher rates could also be a result of the rapidly ageing agricultural workforce in Japan [38]. A large proportion of women worked as clerks, the jobs that are often considered at least risk during economic recessions. Similarly, women in higher socio-economic positions may have access to extensive resources as a result of their widespread networks [39], leading to reduced mortality rates than in other occupational categories.

Our study has several limitations. There is a possibility that the distribution of population is different across occupations as we used data from two different sources for information related to deaths and population. Thus, this study is attributable to numerator-denominator bias. However, the result from the sensitivity analysis in a study by Wada et al. showed a minimal effect of the numerator-denominator bias [7]. The occupation was based on subjective information from the family of deceased women potentially leading to recall bias. As almost $44 \%$ of Japanese women were part-time or irregular workers [14], the deceased women's occupation may not have been declared by the family member. This information could therefore be misleading, because it may reflect long-term occupation rather than any occupation that the deceased woman was engaged in immediately before her death. Some occupations may have been misclassified as unemployed or others if the person quit her job because of serious illness. We used the Japan Standard Occupational Classification to categorise occupations. However, it has been revised several 
times over the years, which may have resulted in bias in our findings. Agricultural workers were the smallest category throughout the study period, and this may be reflected in the calculated age-standardised rates and, hence, trends.

\section{Conclusions}

In conclusion, mortality rates have decreased across all occupational categories over the years, reducing the prevailing inequalities in mortality. However, attention should now be given to agricultural workers to further reduce the mortality gap. Continuous monitoring of mortality trends is essential to ensure better health and wellbeing in Japan.

\section{Supplementary Information}

The online version contains supplementary material available at https://doi. org/10.1186/s12905-022-01621-4.

Additional file 1. Table A1: Rate ratios of mortality rates for the leading causes of death Description of table: Result of Poisson regression analysis.

\section{Acknowledgements}

We thank Melissa Leffler, MBA, from Edanz for editing a draft of this manuscript.

\section{Authors' contributions}

Conceptualisation: BD, KT, SA, KW, SG; Data provision: KW; Data curation: BD KT, SG; Formal analysis: BD, SG; Funding acquisition: KW; Investigation: BD, SG, KT; Methodology: BD, SA, SG; Project administration: KW; Resources: KW; Software: SG; Supervision: KW, SG; Validation: BD, KW, SG; Visualisation: BD, KT, KW, SG; Writing —original draft: BD; Writing — review and editing: BD, KT, SA, KW, SG. All authors read and approved the final manuscript.

\section{Funding}

This work was supported by Grant-in-Aid for Scientific Research (C) (No. 17K09184). The sponsor had no role in the design, analysis, or interpretation of the study result and in writing the manuscript.

\section{Availability of data and materials}

The data that support the findings of this study are available from the Japanese Ministry of Health, Labour and Welfare but restrictions apply to the availability of these data and so are not publicly available.

\section{Declarations}

\section{Ethics approval and consent to participate}

As we obtained de-identified secondary data, ethical approval was not obtained as per the 'Ethical Guidelines for Epidemiological Research' of the Japanese Government. (https://www.niph.go.jp/wadai/ekigakurinri/guide lines.pdf).

\section{Consent for publication}

Not applicable.

\section{Competing interests}

The authors declare that they have no competing interests.

\section{Author details}

'Graduate School of Public Health, St. Luke's International University, Tsukiji, Tokyo, Japan. ${ }^{2}$ Department of Health Policy, National Centre for Child Health and Development, Setagaya, Tokyo, Japan. ${ }^{3}$ Graduate School of Medicine, International University of Health and Welfare, Akasaka, Tokyo, Japan. ${ }^{4} \mathrm{Com}$ munity Empowerment for Health Promotion Programme, Nepal Red Cross Society, Nepalgunj, Nepal.

Received: 19 September 2021 Accepted: 7 February 2022

Published online: 22 February 2022

\section{References}

1. Marmot M, Allen J, Goldblatt P, Boyce T, McNeish D. Fair Society Healthy Lives (The Marmot Review). Strategic review of health inequalities in England post-2010. 2010. https://www.instituteofhealthequity.org/resou rces-reports/fair-society-healthy-lives-the-marmot-review. Accessed 1 May 2021.

2. Sindelar JL, Falba TA, Gallo B. Occupation as a social determinant of health. In: iHEA 2007 6th world congress: explorations in health economics paper. 2008. https://papers.ssrn.com/sol3/papers.cfm?abstract_id= 996092. Accessed 20 Jan 2021.

3. Patel A, Lynn S. Exploring occupation as a determinant of health and its contribution to understanding health inequities. Electronic Thesis Dissertation Repository, Western University. 2014. https://ir.lib.uwo.ca/etd Accessed 20 Jan 2021

4. Marmot M. Social determinants of health inequalities. The Lancet. 2005:365(9464):1099-104.

5. Glonti K, Gordeev VS, Goryakin Y, Reeves A, Stuckler D, Mckee M, et al. A systematic review on health resilience to economic crises. PLOS ONE. 2015:10(4):e0123117.

6. Kim I-H, Khang Y-H, Cho S-I, Chun H, Muntaner C. Gender, professional and non-professional work, and the changing pattern of employmentrelated inequality in poor self-rated health, 1995-2006 in South Korea. J Prev Med Public Health. 2011:44(1):22.

7. Wada K, Kondo N, Gilmour S, Ichida Y, Fujino Y, Satoh T, et al. Trends in cause specific mortality across occupations in Japanese men of working age during period of economic stagnation, 1980-2005: retrospective cohort study. BMJ. 2012;344:e1191.

8. Houweling TA, Kunst AE, Huisman M, Mackenbach JP. Using relative and absolute measures for monitoring health inequalities: experiences from cross-national analyses on maternal and child health. Int J Equity Health. 2007;6(1):15.

9. Mackenbach JP. Should we aim to reduce relative or absolute inequalities in mortality? Eur J Public Health. 2015;25(2):185-185.

10. Kagamimori S, Gaina A, Nasermoaddeli A. Socioeconomic status and health in the Japanese population. Soc Sci Med. 2009;68(12):2152-60.

11. Ikeda N, Saito E, Kondo N, Inoue M, Ikeda S, Satoh T, et al. What has made the population of Japan healthy? The Lancet. 2011;378(9796):1094-105.

12. Suzuki E, Kashima S, Kawachi I, Subramanian SV. Social and geographic inequalities in premature adult mortality in Japan: a multilevel observational study from 1970 to 2005. BMJ Open. 2012;2(2):e000425.

13. Dhungel B, Murakami T, Wada K, Gilmour S. Mortality risks among blueand white-collar workers: a time series study among Japanese men aged 25-64 years from 1980 to 2015. J Occup Health. 2021;63(1):12215.

14. Statistics Bureau of Japan. Labour force survey. Ministry of internal affairs and communications. 2020. https://www.stat.go.jp/english/data/roudou/ index.html. Accessed 24 Mar 2021

15. Ministry of Health Labour and Welfare. Vital statistics of Japan 1980-2015. Vital, Health and Social Statistics Office. 2016. https://www.mhlw.go.jp/ english/database/db-hw/index.html. Accessed 24 Jan 2021.

16. Statistics Bureau of Japan. Population Census 1980-2015. Ministry of Internal Affairs and Communication. 2016. http://www.stat.go.jp/english/ data/kokusei/index.html. Accessed 24 Jan 2021.

17. Ministry of Health Labour and Welfare. Occupational Classification (Revision 4th). The Japan Institute for Labour Policy and Training. 2011. https:// www.jil.go.jp/institute/seika/shokugyo/bunrui/index.html. Accessed 29 Jan 2020.

18. Mathers CD, Fat DM, Inoue M, Rao C, Lopez AD. Counting the dead and what they died from: an assessment of the global status of cause of death data. Bull World Health Organ. 2005;83(3):171-7. 
19. Ministry of Health Labour and Welfare of Japan. Vital Statistics of Japan 2018. Information Policy and Policy Evaluation 2018. https://www.mhlw. go.jp/english/database/db-hw/dl/81-1a2en.pdf. Accessed 25 Dec 2021.

20. Ueshima H. Explanation for the Japanese Paradox: prevention of increase in coronary heart disease and reduction in stroke. J Atheroscler Thromb. 2007;14(6):278-86.

21. Honjo K, Iso H, Inoue M, Tsugane S. Education, social roles, and the risk of cardiovascular disease among middle-aged Japanese women: the JPHC study cohort i. Stroke. 2008;39(10):2886-90.

22. Ikeda A, Iso H, Yamagishi K, Inoue M, Tsugane S. Blood pressure and the risk of stroke, cardiovascular disease, and all-cause mortality among Japanese: the JPHC study. Am J Hypertens. 2009;22(3):273-80.

23. Mannami T, Iso H, Baba S, Sasaki S, Okada K, Konishi M, et al. Cigarette smoking and risk of stroke and its subtypes among middle-aged Japanese men and women. Stroke. 2004;35(6):1248-53.

24. Hori M, Kitamura A, Kiyama M, Imano H, Yamagishi K, Cui R, et al. Fifty-year time trends in blood pressures, body mass index and their relations in a Japanese community. J Atheroscler Thromb. 2017;24(5):518-29.

25. Ikeda N, Gakidou E, Hasegawa T, Murray JL. Understanding the decline of mean systolic blood pressure in Japan: an analysis of pooled data from the National Nutrition Survey, 1986-2002. Bull World Health Organ. 2008;86(12):978-88.

26. Ministry of Health Labour and Welfare. Annual Health, Labour and Welfare Report 2017: Health and Medical Services. 2017. https://www.mhlw.go. jp/english/wp/wp-hw11/. Accessed 31 Mar 2021.

27. Yoshimoto M, Tada K, Hori H, Morota A, Tanabe M, Nishimura S, et al. Improvement in the prognosis of Japanese breast cancer patients from 1946 to 2001 an institutional review. Jpn J Clin Oncol. 2004;34(8):457-62.

28. Zaitsu M, Kaneko R, Takeuchi T, Sato Y, Kobayashi Y, Kawachi I. Occupational inequalities in female cancer incidence in Japan: hospital-based matched case-control study with occupational class. SSM -Popul Heal. 2018;5:129-37.

29. Gilmour S, Kanda M, Kusumi E, Tanimoto T, Kami M, Shibuya K. HPV vaccination programme in Japan. The Lancet. 2013;382(9894):768.

30. Dhungel B, Sugai MK, Gilmour S. Trends in suicide mortality by method from 1979 to 2015 in Japan. Int J Env Res Public Health. 2019;16(10):1794.

31. Gilmour $S$, le Mai P, Nguyen P, Dhungel B, Tomizawa M, Nguyen H. Progress towards health for all: time to end discrimination and marginalization. Int J Environ Res Public Health. 2020;17(5):1696.

32. Schernhammer ES, Colditz GA. Suicide rates among physicians: a quantitative and gender assessment (meta-analysis). Am J Psychiatry. 2004;161(12):2295-302.

33. Agerbo E, Gunnell D, Bonde JP, Mortensen PB, Nordentoft M. Suicide and occupation: the impact of socio-economic, demographic and psychiatric differences. Psychol Med. 2007;37(8):1131-40.

34. Chen J, Choi YJ, Sawada Y. How is suicide different in Japan? Japan World Econ. 2009;21(2):140-50.

35. Martínez-Rives NL, Dhungel B, Martin P, Gilmour S. Method-specific suicide mortality trends in Australian men from 1978 to 2017. Int J Env Res Public Health. 2021;18:4557.

36. Nomura S, Kawashima T, Yoneoka D, Tanoue Y, Eguchi A, Gilmour S, et al. Trends in suicide in Japan by gender during the COVID-19 pandemic, up to September 2020. Psychiatry Res. 2021;295:113622.

37. Fukuda Y, Nakamura K, Takano T. Accumulation of health risk behaviours is associated with lower socioeconomic status and women's urban residence: a multilevel analysis in Japan. BMC Public Health. 2005;5(1):53.

38. Usman M, Sawaya A, Igarashi M, Gayman JJ, Dixit R. Strained agricultural farming under the stress of youths' career selection tendencies: a case study from Hokkaido (Japan). Humanit Soc Sci Commun. 2021;8(1):1-8.

39. Galobardes B. Indicators of socioeconomic position (part 1). J Epidemiol Commun Health. 2006;60(1):7-12.

\section{Publisher's Note}

Springer Nature remains neutral with regard to jurisdictional claims in published maps and institutional affiliations.

Ready to submit your research? Choose BMC and benefit from:

- fast, convenient online submission

- thorough peer review by experienced researchers in your field

- rapid publication on acceptance

- support for research data, including large and complex data types

- gold Open Access which fosters wider collaboration and increased citations

- maximum visibility for your research: over $100 \mathrm{M}$ website views per year

At BMC, research is always in progress.

Learn more biomedcentral.com/submissions 